\title{
FICÇÃO QUE SE REALIZA: O BRASIL URBANO NA OBRA DE SÉRGIO SANT’ANNA
}

Luis Alberto Brandão Santos $U F M G$

\section{REFERÊACIAS BIBLIOGRŔFICAS}

TODOROV, Izveton. A conquista do América: o questāo do outro. 2. ed. Sōo Poulo: Mattins Fontes, 1988 CaMinHA, Pero Voz de. A Carta de Pero Vaz de Cominho. 3. ed. Rio de Joneiro: Agir, 1989. p. 89.

Sérgio Sant'Anna's narratives establish a close dialogue with the contemporary questions. One of these questions is the emergence of a chaotic Brazil, basically urban. This essay aims at approaching Sant'Anna's urban Brazil, discussing the relationship between recognition and uncertainty in reality/language articulation. 
Disponível em http://www.letras.ufmg.br/poslit

"Como fazer literatura aqui "” Essa indagação coloca em relevo a relação entre a literatura e o local onde essa literatura é produzida. $\mathrm{Na}$ obra de Sérgio Sant'Anna, a possibilidade do fazer literário define-se em função desse "aqui", dessa localização física que traz, em si, um conjunto de referências sociais, históricas, políticas, culturais, econômicas. Referências que constituem, em suma, uma realidade específica: a realidade brasileira. A partir da constatação de um profundo vínculo texto/realidade, uma pergunta torna-se pertinente: qual é o olhar que a ficção de Sant'Anna lança sobre o Brasil?

"Em vez de jogar-me na correnteza do rio, jogar-me na correnteza das cidades"2. A decisão do narrador de Confissões de Ralfo nos aponta um aspecto primordial para a caracterização desse olhar. Ao desistir do suicídio e mergulhar no universo das cidades, Ralfo abandona o autocentramento e o subjetivismo existencialista (características fortes das narrativas de $O$ sobrevivente e que ecoam em alguns textos de Notas de Manfredo Rangel, repórter) e inaugura um olhar mais abrangente, um olhar sobre o mundo. Olhar que passa, necessariamente, por uma imagem de Brasil. Essa imagem é, sobretudo, a imagem de um Brasil urbano.

Produzidas a partir do final da década de sessenta, as narrativas de Sérgio Sant'Anna trazem um desejo de sincronia, a busca de um diálogo íntimo com as questões de seu tempo. Uma dessas questōes é, sem dúvida, o crescimento desordenado das grandes cidades. O novo perfil de um Brasil caótico, que se configura através do processo de urbanização, aparece, desse modo, como uma das principais fontes nas quais se nutre sua ficção. Como afirmou Italo Moriconi: "A força da ficção de Sérgio Sant'Anna esteve desde o início em sua firme opção por um tipo de narrativa vertiginosa apoiada na tematização da experiência urbana e na renovação do lugar do coloquial em nossa língua literária"

Moriconi também destaca que a experiência urbana não surge apenas como temática, mas como um certo modo de percepção da realidade, típico dos moradores dos grandes centros: "Fatos, ações, verdades são constantemente deslocados por jogos caleidoscópicos de ironias e desconstruções cujos referenciais concretos estão no jeito de falar e no espírito cético e sarcástico do habitante da cidade grande - este ser

1. SANT'ANMA, 1989. p. 18.

2. SANT'ANMA, 1975. p. 165.

3. MORICONI, 1989. Um filho esperto do "boom", p. 10.
Disponivel em http///www.letras.ufmg.br/poslit

desprovido de ingenuidade, que vive no presente contínuo e está sempre ansiando por alguma outra coisa, que jamais encontra" ". Esse modo específico de percepção e vivência da realidade acaba por determinar um modo específico de elaboração narrativa, calcado, sobretudo, na ótica urbana do narrador. Se é verdade que, como se afirma em Simulacros, "a cidade, além de seus muros e organismos, era também uma categoria dentro das pessoas" ${ }^{5}$ podemos afirmar que, em Sérgio Sant'Anna, a cidade é uma categoria dentro das narrativas.

O Brasil urbano que surge a partir do olhar cético da narrativa de Sant'Anna é, acima de tudo, um Brasil que desmistifica a visão de um país apenas rural e bucólico, primitivo mas paradisíaco, desconhecido e exótico mas generoso e acolhedor. Aquele Brasil estereotipado, forjado nas mentes dos turistas desinformados, é descrito com perfeição em Confissões de Ralfo:

- Ah, sim, o Brasil. Muito bem, o Brasil. Verdes campos floridos, terras férteis e praias maravilhosas, repletas de coqueiros e mulheres nativas de corpo bronzeado, que oferecem ao forasteiro incríveis delícias do amor. $O$ Brasil. De dia trabalha-se sem esmorecimento para o progresso e de noite dançam-se ritmos quentes e sensuais como a rumba e o tango, não é mesmo? Eu adoraria visitar o Brasil. ${ }^{6}$

Essa visão de um Brasil romântico e folclórico aparece encarnada, em Simulacros, na figura de Jorge Amado. De maneira divertida e zombeteira, as personagens dividem-se entre aquelas que admiram a obra de Amado e aquelas que a desprezam. Vedetinha é, como descreve Jovem Promissor, uma "dessas pessoas que lêem um livro brasileiro por ano: o livro do Jorge Amado"? . Jovem Promissor e Velho Canastrão, ironicamente, afırmam que não censuram Vedetinha, argumentando que "tem muita gente que gosta" ${ }^{\natural}$. Mas a discussão mais interessante se dá entre o dr. $\mathrm{PhD}$, significativamente um cientista norte-americano, e Jovem Promissor, significativamente brasileiro e aspirante a escritor. $\mathrm{N}$ a divergência entre as duas personagens, fica nítida a opção de ruptura da ficção posterior à década de sessenta - portanto, a ficção de Sérgio Sant'Anna - com a tradição

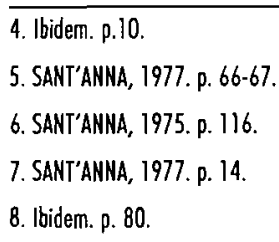

8. Ibidem. p. 80. 
Disponível em http://www.letras.ufmg.br/poslit

oriunda do modernismo das décadas de trinta e quarenta. Vejamos um trecho da discussão:

O dr. PhD disse que o novo livro de Jorge Amado demonstrava mais eloqüentemente do que nunca a vocação do romancista para retratar a alma e os costumes do povo brasileiro, particularizados numa de suas regióes culturalmente mais coloridas, o Estado da Bahia. E que a maioria dos autores mais novos do Brasil, ao contrário, com vazias e excessivas preocupações formais, não conseguia transcender o circuito fechado da classe média.

Resenhando Simulacros, Benício Medeiros comenta que Jorge Amado seria o "saco de pancadas favorito para uma geração que carrega as cicatrizes de algumas ilusões despedaçadas" ${ }^{\prime \prime}$. Esse sentimento de desilusão, de anti-ufanismo, é que faz com que a ficção reivindique para si a representação de um outro Brasil. Um Brasil que deixa de corresponder àquela imagem saudosa de um país paradisíaco ou à imagem utópica de "país do futuro", veiculada a partir dos anos JK e reforçada durante o período do "Milagre Brasileiro". Como enfatiza Luiz Fernando Emediato, "a literatura de Sérgio Sant'Anna é a literatura da industrialização desenfreada, caótica e desumana, da violência, do hedonismo, da alienação e da crise. Dentro de seus livros qualquer um pode ver o próprio rosto, o rosto do Brasil e do brasileiro urbano e moderno. Um rosto pálido e feio, para desgraça nossa, amargamente verdadeiro"'!. Um Brasil que passa a não se adequar à expectativa do olhar estrangeiro, interessado, sobretudo, em imagens de cartão postal. Comentando o mercado editorial norteamericano, a personagem do editor, no conto "O duelo", observa: "Pena que eles lá prefiram o nosso lado telúrico, a terra, o campo, como se $a$ cidade só pertencesse a eles. Mas pelo menos năo são tão radicais quanto os franceses nesse ponto, o jorgeamadismo deles"'2.

Reivindicando o direito "à cidade", a ficção de Sant'Anna propõe um duplo deslocamento: muda o objeto da ficção (o universo a ser retratado é um universo estritamente urbano) e muda a linguagem dessa ficção (a mudança de objeto exige a busca de novas formas de narrar). Não se trata, portanto, de abdicar da necessidade de representar a realidade brasileira,

\footnotetext{
9. Ibidem. p. 162 .

10. MEDEIROS, 1978. Alegorios urbanos, p. 3.

11. EMEDIATO, 1986. Vonguordo e prozer, p. 8.

12. SANT'ANNA, 1989. p.39.
}

mas de somar, a essa necessidade, uma discussão sobre as formas possíveis para tal representação. Nesse sentido, sua ficção está integrada a um movimento mais amplo que ocorre na literatura brasileira a partir dos anos sessenta. É o que acentua o próprio Sérgio Sant'Anna, através da voz do narrador do conto "O concerto de João Gilberto no Rio de Janeiro":

Em 1978 dei no Museu de Arte Moderna do Rio de Janeiro um curso sobre a ficção a partir dos anos 60 . Durante este curso foram valorizados principalmente os livros que não só discutiam a sociedade brasileira nas décadas de sessenta e setenta, incluindo os traumas políticos, como também colocavam em questão o próprio narrar disso tudo. Livros passíveis de mais de uma leitura, como se diz por aí. $\mathrm{E}$ nessa lista foram incluídos $A$ Festa, do Ivan Angelo; o Galvez, do Márcio; o Zero, do Loyola; o conto "Intestino Grosso", do Rubem Fonseca, etc. Não porque fossem livros melhor escritos do que outros, mas porque traziam esta postura que me parecia adequada à época. Uma época que questionou a narrativa. Não incluí a mim próprio, por falsa modéstia. ${ }^{13}$

Nesse movimento, entra em debate o conceito de realidade. A realidade deixa de ser entendida como um mero tema, um objeto a ser passivamente representado. Passa, então, a ser considerada enquanto um processo que é, também, um processo de linguagem. Na certeza de que a realidade é indissociável da forma como é percebida, trazer, para o universo da ficção, uma discussão sobre a realidade significa discutir os próprios mecanismos de representação.

Buscar a realidade como objeto para a ficção significa construir a fição como um objeto produzido por essa realidade. Assim, a uma realidade urbana, corresponde uma ficção urbana. A uma vivência vertiginosa nas grandes cidades, correspondem vertigens narrativas. A visão caleidoscópica da vida incorpora-se ao olho do texto. Se a realidade, nos tempos atuais, progressivamente se ficcionaliza, através do poder de penetração cada vez mais intenso dos meios de comunicação de massa, a ficção de Sant'Anna se "realiza", reafirmando seu desejo de incorporar a realidade. A incorporação da realidade acarreta, desse modo, uma progressiva afirmação da ficcionalidade. Nas palavras do narrador de "O concerto de João Gilberto no Rio de Janeiro": "Mas aqui, neste texto, há palcos de verdade e uma parte de 'não-ficção'. Estaremos, agora, diante de um novo realismo na literatura brasileira? Um novo realismo que assume uma forma fragmentária? Pois está difícil, hoje em dia, não escrever em

13. SANT'ANNA, 1982. p. 215. 
fragmentos. Porque a realidade, cada vez mais complexa, também se estilhaçou"14.

$\mathrm{Na}$ medida em que linguagem e realidade se condicionam mutuamente, a tarefa de procurar o Brasil nos textos de Sérgio Sant'Anna não se reduz à identificação de acontecimentos, nomes ou especificidades năo se reduz à identificação de articula com movimentos de linguagem que problematizam o modo como esses nomes, acontecimentos e procificidades culturais são representados. Já que a realidade é sempre acompanhada por um conjunto de discursos e percepçóes que se formulam em torno dela, um reconhecimento crítico da realidade deve, necessariamente, colocar em questão o modo como se manifestam essas percepções e esses discursos.

Esse simultâneo reconhecimento/questionamento da articulação realidade/linguagem é ressaltado por Flora Sussekind no seu comentário das cenas "Interrogatório (1)" e "Interrogatório (2)", de Confissōes de Ralfo. Tais cenas se inserem numa preocupação mais ampla da literatura brasileira Tais cenas in 1975 , procurou trazer à tona uma revisão dos que, a partir díticos que marcaram os Governos Militares sobretudo de 1968 a 1974. Nessa revisão, uma das temáticas mais exploradas foi, sem dúvida alguma, a temática da tortura física, executada nos porões da Ditadura. Flora Sussekind mostra que o texto de Sant'Anna caminha da Ditadura. Flora Susse tendência, dominante na época, de buscar um retrato jornalístico, documental, explorando minúcias realistas.

$\mathrm{Na}$ contracorrente, a cena de tortura em Confissöes de Ralfo trapaceia essa demanda, rompendo com a expectativa de uma abordagem dolorosa e dramática. Sérgio Sant'Anna constrói "bufonerias da tortura"'s, colocando na boca dos torturadores perguntas insólitas, que lembram uma espécie de argüição oral absurda. Perguntas do tipo "Quem descobriu o Brasil?", "Quem escreveu a história de MacBeth?", "O que é uma heresia?", "Como se joga o gamão?", "O que é um batráquio?" revelam, através do nonsense, que o autoritarismo não existe apenas numa situação específica de tortura, mas é uma prática difundida nos diversos discursos que compõem a vida social (o discurso religioso, o discurso científico, o discurso estético, etc.). Nas palavras de Flora Sussekind: "Sérgio Sant'Anna utiliza-se, pois, do 'sem sentido' desses diálogos tanto para afirmar a

14. lbidem. p. 211.

15. SUSSEKIND, 1985. p. 47. irracionalidade mesma da situação carcerária, quanto para desdramatizar sua representação da tortura. Tanto para obrigar o leitor a perceber a gratuidade da violência, quanto para impedi-lo, via humor, de derramar lágrimas amargas pelo que o texto sugere" 16 .

Assim, através dessa desdramatização, o texto de Sant'Anna interessa-se năo apenas por abordar a tortura em si, mas por tecer um comentário crítico sobre a forma como se dava a recepção do tema "tortura" naquela época. Colocar em questão não apenas a tortura enquanto uma realidade, mas também a tortura enquanto um discurso. Se a repressão política é um elemento fundamental para a caracterização de um momento histórico brasileiro específico, também é histórica e específica a realidade discursiva em torno desse momento. Segundo Flora Sussekind, "essa ávida leitura da experiência carcerária ou da narrativa dos sofrimentos alheios parece apontar no sentido de um mea culpa da classe média que apoiou o golpe militar de 1964 e a subseqüente militarização da sociedade brasileira e, desencantada, começa a se penitenciar ficcionalmente pela repetida leitura de suas conseqüências"1". É para atingir esse objetivo de tratar realidade e discurso de maneira simultânea que o texto opta por uma ruptura com a expectativa do leitor, procurando "desautomatizar o olhar de um leitor também acometido, e em graves proporçōes, da 'síndrome da prisão' anunciada por Torquato Neto em 1970"18.

Essa forma de olhar a realidade, através da elaboração de uma linguagem que se articula com o enfoque que um certo momento histórico dá a essa realidade, também está presente em Amazona. Aproximando-se da linguagem dos meios de comunicação de massa, a narrativa de Amazona constrói-se como uma espécie de seriado de televisāo, com seu ritmo nervoso, suas coincidências insólitas, seus enredos mirabolantes, seus chavões irresistíveis. Entretanto, Amazona também é, como chama a atenção José Figueiredo, um texto através do qual "Sérgio Sant'Anna deu contornos mais precisos à dimensão política da história - passada entre os últimos meses do regime militar e a posse do Presidente Sarney"19. Como é confirmado por José Maria Cançado, há, em Amazona, a presença de "todo o 'mobiliário' de uma época, no caso a do fim da ditadura, governo

\author{
. bidem. p. 51 \\ 17. SUSSEKIND, 1985. p. 44. \\ 18. Ibidem. p.51. \\ 19. FIGUEIREDO, 1986. Dionisio, Amazona, Diana: a nova mulher, dona da própria história.
}


Figueiredo: as canhestras tentativas de golpe, a indigência incorrigivel das nossas elites, os antagonismos na sociedade, as ambigüidades e vacilações na transição democrática"20.

Amazona opera, assim, uma composição de um espaço reconhecidamente ficcional - que é exacerbado em direção à farsa -, com um espaço, quase jornalístico, de referências precisas a nomes, datas e fatos concretos. Nessa composição, os limites que separam esses dois espaços se indeterminam. Quanto maior parece ser a fidelidade do ato de trazer para o texto a realidade, maior é a volúpia com a qual a fiç̧ão dela se apodera. Tal procedimento indica uma mudança de perspectiva na representação da história brasileira recente. Como afirma Silviano Santiago,

Amazona se soma aos textos de legítima ficção que estão se sucedendo ao relato das memórias dos ex-jovens revolucionários. Portanto, os acontecimentos transcorridos no Brasil a partir de 1964 não são escritos como que de maneira colada à experiência do indivíduo, deixando falar a sinceridade do autor/ator, mas passam pelos labirintos da imaginação, pelo distanciamento crítico e até pelo voyeurismo. ${ }^{21}$

No entanto, o mais interessante em Amazona é que a mistura ficção/realidade não é gratuita. Nota-se, na verdade, um intuito deliberado de se enfatizar a "aparência irreal que possui a realidade" 2 . Ao desejar produzir um texto de forte conotação política e de intensa proximidade com os acontecimentos do período, Sant'Anna opta pelo desenvolvimento de uma linguagem espetacularizada. Tal opção se justifica, exatamente, pelo fato de a realidade - em especial a política - já ter iniciado seu processo vertiginoso de espetacularização. Processo que culminaria, poucos anos mais tarde, na eleição, para Presidente da República, de Fernando Collor de Mello.

Dessa forma, Amazona sintoniza-se não apenas com o Brasil político dos anos que desembocam na "Nova República", mas também com o próprio modo como o país, a partir dessa época, se faz político; o modo como a articulação dos discursos políticos passa a configurá-lo.

Podemos citar, ainda, mais dois exemplos marcantes da conjugação entre discussão da realidade e discussão da linguagem aplicada,

20. CANÇADO, 1986. Caģadar zen da perteiçõo.

21. SANTIAGO, 1986.. Para apetites apurados.

22. SANT'ANNA, 1986. p. 123
Disponível em http://www.letras.ufmg.br/poslit

pela ficção de Sant'Anna, no delineamento de um retrato do Brasil. Em Um romance de geração, a abordagem dos vários aspectos do projeto políticoexistencial da juventude brasileira - em especial, a juventude intelectualizada - na segunda metade dos anos sessenta é feita através da incorporação desses aspectos na estrutura narrativa. Desse modo, como analisa Heloisa Buarque de Holanda, "a peça encena o projeto inacabado, romântico, radical e extraordinariamente inviável que, na certa, povoou, pelo menos em algum momento, o imaginário de todos nós" ${ }^{33}$. Mimetizando esse projeto, exatamente para discuti-lo, Sant'Anna cria uma peça de teatro verborrágica, inacabada e impossível de ser encenada. Peça que é, na verdade, como observou Wilson Martins, "uma perpétua promessa da peça a que assistimos (ou lemos), sem realmente começar a sê-la"24.

Já em $A$ tragédia brasileira, lança-se o foco sobre a questão do processo de modernização do país. Fazendo oscilar a narrativa entre 0 princípio dos anos sessenta e a década de oitenta, Sant'Anna põe em relevo o hiato entre o projeto de um Brasil moderno e a sua concretização. Para mostrar a indefinição entre a grande cidade e o latifúndio, entre o progresso e a miséria, entre a cultura cosmopolita e os mitos mais arcaicos, $A$ tragédia brasileira mostra-se como um esboço de texto, uma narrativa que vai sendo permanentemente retocada. Tangenciando uma tragicidade patética que faz eco ao texto homônimo de Manuel Bandeira ${ }^{25}$, o texto de Sant'Anna forma um painel híbrido e fragmentado, que parece avançar, assim como o Brasil, através de um caminho repleto de sinalizações labirínticas.

Esses exemplos, e muitos outros possíveis, demonstram que o Brasil é um objeto privilegiado pelo olhar da narrativa de Sérgio Sant'Anna. Demonstram também que a tentativa de marcar, no texto, a presença desse objeto não exclui a necessidade de se investigar continuamente os olhares - dentro e fora da narrativa - que o retratam. Olhar o Brasil corresponde, assim, a elaborar uma cena na qual circula uma profusão de olhares sobre o Brasil. A transformação da realidade brasileira em discurso ficcional se dá através da geração de um espaço de embate entre distintos discursos sobre a realidade. Cria-se uma imagem de Brasil cotejando-se imagens diversas de Brasil. Imagens que se interrogam enquanto imagens: realidade que se questiona enquanto linguagem.

23. HOLANDA, 1982. A luta dos suffocados e o prozer dos retornados, p. 10.

24. MARTINS, 1982. Um romance de geraçāo. Traduy̧ōo minho.

25. Cf. BANDEIRA, 1966. p. 146-147. 
Explorar o poder de referência da linguagem é trabalhar no limite mesmo onde a realidade extratextual surge como uma visão, dentro do texto, reconhecível (há o desejo de compartilhar uma percepção sobre a realidade, de propor uma perspectiva coletiva) e, simultaneamente, irreconhecível (há o desejo de se deslocar a percepção automatizada e massificada da realidade). Entre narrativa e leitor, busca-se, ao mesmo tempo, a convergência e a divergência de olhares. O Brasil delineado é, desse modo, um Brasil verdadeiro e absurdo, banal e estranhíssimo, sensato e alucinado, óbvio e surpreendente. Entre texto e realidade, identificação e desencaixe: dentro e fora.

Crível e incrível.

\title{
VIVIRSE EN LA LITERATURA: LOS NARRADORES EN LAS NOVELAS DE HAROLDO CONTI
}

Graciela Ravetti $U F M G$

REFERÊNCIAS BIBLIOGRÁFICAS

\author{
RESUMO
}

BANDEIRA, Monuel. Estrela do vida inteiro; poesios reunidas. Rio de Janeiro: José Olympio, 1966. CANCADO, José Moria. Corodor zen do perfeiçōo. Leia, São Poulo, p. 36, obril 1986.

EMEDIATÓ, Luiz Fernondo. Vanguorda e prozer. O Estodo de Sä́a Poulo, Sõa Poulo, 04 maio 1986. Coderno 2, p. 8.

IGUEEREDO José. Dionísio, Amozona, Diona: a novo mulher, dano do próprio histório. O Globo, Rio de Janeiro, 06 abril 1986. HOLANDA, Helóiso Buorque de. A luto das sufocodos e o prozer dos retornodos. Jornal do Brasil Rio de Joneiro, 13 fev. 1982. Coderno B, p. 10 .

MARTINS, Wilson. Um romonce de geroçāo. World Literofure Today, Norman, University of Oklohomo, USA, winter 1982 MEEEROSS,

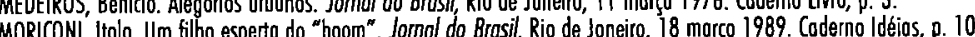
.

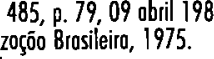

Simulacros. Rio de Janeiro: Civilizarōo B Brosileiro: 1977.

O concerto de Joũo Gilberto no Rio de Joneiro. Sũo Poula: Ático, 1982

Amozono. Rio de Janeiro: Novo Fronteira, 1986.

- A senhorito Simpsan. São Paula: Componhio das Letros, 1989.

SUSSEKIND, Floro. Literofuro e vida literério. Sóo Poulo: Jorge Zohor, 1985.

O presente trabalho faz parte de uma pesquisa que toma como objeto os quatro romances de Haroldo Conti, escritor argentino contemporâneo, com o objetivo de construir um modelo das estruturas literárias em relação com o imaginário do texto; construção que permita uma leitura dos imaginários sociais de toda uma comunidade. É assim que abordamos os modos de representação literária dos narradores como um dos modos de naturalizar as convenções . 